\title{
Membrane Separation Theoretical and Applicable Considerations for Optimum Industrial Bioprocessing
}

Timothy Lee Ph.D* and Tony D'Amore Ph.D

Sanofi pasteur Limited, USA

\section{Introduction}

In a biochemical process, the highest operating and equipment costs can often be found in the area of downstream processing. Approximately $50 \%$ of the manufacturing costs are accounted for in the downstream processing part of the overall process. The downstream processing step is defined as the step to recover and purify the product after fermentation. The cost of the downstream processing step takes into account the capital and operational expenses in delivering a purified product to market; often times, the operational expenses encompassing equipment and buffer preparation, process condition, equilibration and cleaning amount to the majority of the cost. As a result, any optimization that would enhance product yield improvement would be beneficial to lowering the manufacturing costs and making the standard cost of the product more attractive.

The optimization of primary recovery step within the downstream process will be discussed in detail within this chapter. Primarily, this chapter will be focused on membrane separation technologies and techniques used in obtaining clarified product of high recovery and suitable purity for column chromatography. The membrane separation technology would pertain to areas relevant to the manufacturing process: (1) Clarifying the cells from the fermentation broth and conditioning the cells for mechanical or chemical disruption, (2) Clarifying the product from a homogenate of cellular debris after a disruption process, (3) Clarifying an extracellular product from the culture after fermentation, and (4) concentration and diafiltration of a clarified product for chromatography.

Optimization of the membrane separation involves optimizing several process-specific parameters such as temperature, specific cake resistance of cellular material, fluid viscosity, transmembrane pressure, cross-flow velocity, membrane surface area and type, membrane load, quality of the fermentation culture and homogenization conditions. This chapter will go into detail with the above process parameters and how each affects the protein flux during the membrane separation. This chapter will also focus on advantages and challenges in using new technologies such as disposable charged membranes available on the market for clarification purposes and compare those technologies to more conventional and traditional methods of capture and separation. There are many ways of recovering biological products and the decision the scientist or engineer has is to decide what method is best to achieve the most efficient separation process to meet the growing demands of the biotechnology industry. The development of the primary recovery step emphasis is on the need to design a process that is scalable and feasible in operation and also yielding a high quantity of product. The development phase is the best time to test and approve the process parameters and membrane type used for recovering the biological product before the process is transferred to the manufacturing environment.

The chapter is broken down into subsections for discussion:

1) Critical process parameters and theoretical considerations impacting product flux and recovery. a. temperature,

b. specific cake resistance of cellular material,

c. fluid viscosity,

d. transmembrane pressure,

e. cross-flow velocity,

f. membrane surface area and type,

g. membrane load,

h. quality of the upstream fermentation culture and homogenization conditions.

2) Micro-filtration/Ultra-filtration as a method of separation.

3) Depth-filtration as a method of separation.

4) Industrial options of separation using charged membranes and resins.

Section 2 will be discussing the process-specific parameters affect product recovery flux and areas within the process where optimization can be performed to increase throughput and decrease cost. Section 3 covers micro-filtration and ultra-filtration as conventional methods of membrane separation used within the biotechnology industry. Although the micro-filtration process is a method used in industry due to its scalability, high flux profiles and relatively low costs, it may sometimes yield low protein product recovery. If process conditions are not optimized or considered, the result may lead to a build-up of the concentration polarization layer causing fouling or poor product recovery. This section will cover the difficulties associated with this technology. Section 4 will introduce the depth-filtration technology and its applicability within the research and development phase of the project prior to transfer to manufacturing. While the depth filtration technology can efficiently clarify protein from the fermentation harvest, scalability, operational handling and cost of this technology limits its use at higher scales of $200 \mathrm{~L}$ or more.

Section 5 outline alternative solutions to membrane separations by using direct capture to facilitate bio-burden removal and product recovery. Direct capture utilizes anionic or cationic exchangers within a single manufacturing step to bind the product of interest while separating residual cellular material and subsequently purifying the product. This section will cover the advantages and challenges of using direct capture, as a disposable technology, from the research to the manufacturing phase of the project.

There are chromatographic applications like expanded-bed adsorp-

*Corresponding author: Timothy Lee, Sanofi pasteur Limited, Tel: 416-667-2426; E-mail: Canadatim.lee@sanofipasteur.com

Received July 07, 2011; Accepted July 07, 2011; Published July 30, 2011

Citation: Lee T, Amore TD (2011) Membrane Separation Theoretical and Applicable Considerations for Optimum Industrial Bioprocessing. J Bioprocess Biotechniq 1:101e doi: 10.4172/2155-9821.1000101e

Copyright: (c) 2011 Lee T, et al. This is an open-access article distributed under the terms of the Creative Commons Attribution License, which permits unrestricted use, distribution, and reproduction in any medium, provided the original author and source are credited. 
tion which are intended to replace the clarification and purification steps to a single step. These applications have advantages of simplifying the overall manufacturing process. This section explores the use of direct adsorption and membrane separation, using a mesh filtration screen of specific pore size to achieve clarification and purification within a single step. This method can be applied simply, inexpensively, and consistently within a manufacturing environment. Section 5 outlines the potential of using batch clarification to recover proteins with high yields enabling the re-use of the resins for further operations. It will cover the economic and business costs within a production environment to compare its application to current conventional equipment of separation.

\section{Critical Process Parameters and Theoretical Consider- ations}

\section{Filtration theory and scale-up considerations}

The determination of the filterability of the fermentation material is important in order to understand the process time and also the characteristics of the filtered biomass being investigated. A specific cake resistance, $\alpha$ (units of $\mathrm{m} / \mathrm{kg}$ ) can be determined by a simple filtration experiment of filtering the fermentation cell material through a $0.2 \mu \mathrm{m}$ cellulose nitrate membrane (Whatman, UK) with a fixed surface area and measuring the mass of filtrate being collected every few seconds at a constant pressure of filtration. The change in the permeate volume (V) in grams with time $(\mathrm{t})$ in seconds is measured under constant pressure and a plot of time/filtrate volume against filtrate volume ( $t / \mathrm{V}$ versus $\mathrm{V})$ should produce a linear slope [1].

$$
\text { slope }=\frac{\alpha \mu \mathrm{C}}{2 \mathrm{~A}^{2} \Delta \mathrm{P}}
$$

The linear slope is described in the equation where:

$\alpha=$ cake resistance $(\mathrm{m} / \mathrm{kg})$

$\mu=$ filtrate viscosity (Pa.s)

$\mathrm{C}=$ concentration of the feed $(\mathrm{g} / \mathrm{L})$

$\mathrm{A}=$ filter medium area $\left(\mathrm{m}^{2}\right)$

$\Delta \mathrm{P}=$ applied pressure $(\mathrm{Pa})$

If the broth characteristics, surface area and pressure are kept constant, then the filtration time required to separate a given volume of broth using a specified filter area, A, can be easily determined.

$$
\text { Filtration time }=\frac{\alpha \mu \mathrm{CV}^{2}}{2 \Delta \mathrm{PA}^{2}}
$$

For the modular design of tangential-flow filtration configurations, several scale-up parameters need to be considered and kept constant during the operation:

1. The inlet and outlet pressures

2. The tangential flow velocity

3. The flow channel sizes

4. The membrane characteristics such as its type and configuration test data from one design cannot directly be used to design another type of geometry

5. The feed stream properties - test slurries should be representative of the actual process stream

With respect to point (5) above, changing the upstream fermentation conditions may have a very huge impact on the process permeate flux (flow rate/surface area of membrane) and it is advisable that the fermentation and recovery experiments be performed in parallel at the bench-scale first before any attempt to reproduce the process at a larger scale. A very common scale-up parameter is to scale up according to constant flux rate. This will involve increasing the surface area of the filtration module to maintain constant flux rate at the larger scale. Also, the biochemical properties play a very important role in the filterability as well as the recovery of the product. Although, many experiments tend to use flow rate as a measure of how successful a recovery operation is, it is also important to measure the protein recovery during the clarification operation. If the protein to be clarified is in a homogenate slurry, it is important to measure the amount of protein recovered in the permeate stream. If the protein product to be separated is in a homogenized slurry, then the product transmitted across the membrane as well as the rate of filtration are both important measurements in determining the success of a clarification process.

\section{Theoretical considerations}

Temperature: An increase in fluid process temperature may result in a higher disruption rate. It was reported that an increase of 1.5 -fold in disruption rate was seen in a $25^{\circ} \mathrm{C}$ increase. An increase in temperature may be unfavorable as the increase in temperature may cause inactivation/degradation of the product if the protein is produced. As the homogenization process depends on the volume of the material and the processing rate through the homogenizer, appropriate cooling may be essential to keep the temperature at a suitable level to maintain the stability of the protein.

Specific cake resistance of cellular material: The nature and composition of the cells (i.e. unicellular compared to filamentous organisms) are big factors in the disruption mechanism of the cell. For example, the rate of disruption of cells such as yeast is known to be strongly dependent on pressure while the rate of release of soluble proteins from filamentous organisms such as Rhizopus nigricans, only required weaker pressures (i.e. 100 bar) at one pass through the homogenizer (Kesharvarz et al., 1990). The breakage mechanism is, therefore, dependent on the cell morphology as well as upon the structural characteristics of the suspension. At higher concentrations (i.e. above $22 \mathrm{~g} / \mathrm{L}$ dry cell weight for Rhizopus), cells form intertwined structures which may settle into a cellular bridging network which may block the orifice of the homogenizer (Kesharvarz et al., 1990). In addition, the structural aspects of the organisms may also affect cell disruption. For example, animal cells, because they do not possess any cell wall, are highly susceptible to disruption in comparison to bacteria. Gram-negative bacteria are easier to break than gram-positive bacteria, which in turn are easier to break than yeast (Kesharvarz, 1997).

Fluid viscosity: The viscosity of the fluid is the result of RNA and DNA contents being released from the cells and changing the fluid characteristics. The main contribution towards viscosity is the DNA molecules. The DNA polymer is shear-sensitive and degrades easily into fragments after several passes through a high-pressure homogenizer, resulting in reduced homogenate viscosity. The reduction in the homogenate viscosity is desired in order to improve solid-liquid separation. One way of reducing the homogenate viscosity is to increase the operational temperature. However, this approach is only appropriate if the protein product is not susceptible to heat denaturation. Another method in reducing the homogenate viscosity may be to introduce DNA lytic enzymes, which degrades the DNA molecules. It is worth noting that addition of any chemical to the suspension may require removal at a later stage and should be carried out with caution.

Transmembrane pressure: In the dead-end filtration method, the fermentation broth is passed through a filter medium, which prevents the passage of solids but permits liquid and solubles to pass. The transmembrane pressure or the driving force can be vacuum, gas pressure 
or pump pressure. In a tangential-flow filtration operation, the transmembrane pressure is controlled by the inlet, outlet and filtrate pressure valves during operation. The effect of transmembrane pressure on filtration flux is an important variable to optimize in order to control membrane fouling and is discussed further in Section 3.

Cross-flow velocity: Cross-flow filtration operation is the process whereby a driving force is applied across a semi-permeable membrane, while maintaining a tangential flow of the feed stream parallel to the separation surface. The aim is to provide sufficient shear close to the membrane surface, thereby keeping the solids and other particulate matter from settling on and within the membrane structure.

\section{Membrane surface area and type}

Dead-end filtration: In dead-end filtration, the two types of filters usually employed for the operation are depth filters and absolute filters. Depth filters are made from fairly porous fibrous materials (i.e. ceramic, cellulose fiber, sintered metal, glass wool, and celite) such that the characteristic pore size between fibers is greater than the minimum size of the materials to be removed. Particle removal is based on the probability that a particle will be retained in the filter. Depth filters are particularly useful in removal of suspended solids (i.e. cellular debris) and can aid in lowering the cost of the operation significantly if the right type and sequence is used.

Absolute filters, on the other hand, are used usually at the final stages of the separation process. The types of membranes used (i.e. ultrafiltration, micro-porous, macro-porous) have maximum pore sizes less than the minimum size of the particles to be removed. The mechanism of filtration is primarily absolute size exclusion. In addition, particle accumulation around an open pore can cause bridging. These particles can then provide a filtration medium, or a secondary layer, that is more efficient than the original filter itself. Lastly, there can be non-specific adsorption of particles to the solid portion of the filter. Absolute filters are quite effective in physically separating micro-organisms from the media. As a result, for media sterilization, one would employ pre-filtration with a depth filter followed by an absolute sterilizing filter.

Cross-flow filtration: Tangential flow filtration is used for a variety of separation processes, and it is common to classify these membranes into the following areas:

a. Micro-filtration: separation of particulates, typically $0.02-10 \mu \mathrm{m}$ b. Ultra-filtration: separation of particulates and polymeric solutes in the $0.001-0.2 \mu \mathrm{m}$.

c. Hyper-filtration: also relates to reverse osmosis, where ionic solutes, typically less than $0.001 \mu \mathrm{m}$, are separated.

Micro-filtration (MF) and ultra-filtration (UF) are the most widely applied membrane processes in the primary recovery stages. The membrane material is either polymeric or inorganic. The most common polymers are cellulose nitrate/acetate and polysulfone. Inorganic membranes tend to be ceramic based, i.e. alumina with a zirconia coating. Cross-flow micro-filtration is commonly used to remove suspended particles from a process fluid and covers operations such as the recovery of cells from fermentation broth and the clarification of cell debris homogenates. Ultra-filtration, on the other hand, is an effective technique for concentrating, or separating smaller particulate matter (i.e. salt), as well as dissolved molecules of different sizes (i.e. buffer). Ultrafiltration can also be used in certain areas of bio-processing such as (a) initial cell separation from fermentation or culture medium, (b) size fractionation of protein solutions and (c) recycling of biomass in continuous fermentation applications.

The membrane housings are available in the five different configurations:

a. tubular,

b. flat sheet,

c. hollow fibre,

d. spiral wound,

e. vibrating membrane system

The 5 different configurations can be used for fermentation broth and homogenate clarification, although the susceptibility to blockage and the low working pressure limitation of the hollow fibre and spiral wound modules are limited in their use especially with highly viscous fermentation broth. The characteristics of the 5 different module configurations are mentioned in Table 1 [2].

The separation performance of tangential flow filtration is a function of:

1) Membrane characteristics - pore size, biochemical properties (i.e. hydrophobic, hydrophilic in nature), permeability,

2) Fermentation broth - rheological properties of the retentate, solute (i.e. biomass) composition and concentration, morphology and size,

3) Hydrodynamics - tangential velocity, laminar/turbulent flow, temperature, shear generated across the membrane surface

\begin{tabular}{|c|c|c|c|c|c|c|c|}
\hline & Channel size & Cross-flow velocity & Reynolds number & Cleanability & $\begin{array}{l}\text { Surface area to } \\
\text { volume ratio }\end{array}$ & Liquid hold-up & $\begin{array}{l}\text { Energy consump- } \\
\text { tion }\end{array}$ \\
\hline Tubular & Large & $2-6 \mathrm{~m} / \mathrm{s}$ & $>104$ & $\begin{array}{l}\text { Easy to clean } \\
\text { (Membrane } \\
\text { replacement is } \\
\text { simple) }\end{array}$ & Low & High & High \\
\hline Hollow fibre & Narrow & $0.5-2.5 \mathrm{~m} / \mathrm{s}$ & $500-3000$ & $\begin{array}{l}\text { Easy to clean } \\
\text { (high membrane } \\
\text { cost) }\end{array}$ & High & Low & Low \\
\hline Spiral wound & Narrow & $0.5-1.5 \mathrm{~m} / \mathrm{s}$ & $500-1000$ & $\begin{array}{l}\text { Reasonably eco- } \\
\text { nomic } \\
\text { (membrane can } \\
\text { collapse) }\end{array}$ & High & Low & Low \\
\hline Flat sheet & $\begin{array}{l}\text { Open/ } \\
\text { narrow }\end{array}$ & $2-3 \mathrm{~m} / \mathrm{s}$ & $>10^{4}$ & $\begin{array}{l}\text { Easy to clean } \\
\text { (Membrane } \\
\text { replacement is } \\
\text { simple) }\end{array}$ & Low & moderate & moderate \\
\hline Vibrating Membrane & Open/ Narrow & $2-3 \mathrm{~m} / \mathrm{s}$ & $>10^{4}$ & $\begin{array}{l}\text { Easy to clean but } \\
\text { Membrane replace- } \\
\text { ment is difficult }\end{array}$ & Low & moderate & High \\
\hline
\end{tabular}

Table 1: The characteristics of cross-flow module configurations. 
4) Transmembrane pressure- driving force across the membrane.

Membrane load: The cell concentration plays a crucial role in the clarification of cellular biomass. The cell biomass is an important variable to be controlled during the process optimization of the upstream fermentation and homogenization conditions to be able to ensure consistency during membrane operations. The cell concentration would affect the number of depth or nominal filters used for clarification and are an important variable for optimization during the microfiltration operation. A concentration and cell wash step is usually performed after fermentation in order to minimize the volume of buffer consumed during the conditioning step. However the degree of concentration is required to be optimized at a small-scale prior to manufacturing.

\section{Quality of upstream fermentation and homogenization conditions}

Fermentation growth conditions: Growth conditions have a major effect on the cell disruption kinetics. It has been shown in the disruption of E.coli cells that the batch cultures grown on synthetic medium were easier to disrupt (i.e. lower pressures and passes) than those grown on complex medium (Gray et al., 1972). Other studies have also shown that cells grown at a higher specific growth rate were easier to disrupt than cells grown at a lower specific growth rate (Engler and Robinson, 1994). This is possible as cells grown at a higher specific growth rate may not produce a stronger cell wall structure than cells grown at lower specific growth rate and therefore are may be more susceptible to cell disruption. Similarly, cells harvested during the log phase of growth are more susceptible to breakage through homogenization than those from the stationary phase. It is well known that cells from the stationary phase commonly have a stronger cell wall structure than those in the log phase where the cells are focused more on protein synthesis than strengthening their cell wall structure.

Another parameter influencing the pressure required for cell breakage is the location of the product within the cell. A cytosolic soluble product may be easier to release than a membrane bound protein (Edebo, 1983) or one located in the vacuole (Follows, 1971). The nature of the product is also important, for example, whether it is an easily degradable enzyme or an inclusion body or a bio-degradable thermoplastic such as poly (hydroxybutyrate) (PHB).

Cell Disruption using homogenization: In the recovery of intracellular proteins, cell disruption is a very significant step. This is because the efficiency at this step of operation affects the downstream operations and losses occurring at this initial stage cannot be regained. If proteins are expressed intracellularly, high-pressure homogenization has been commonly used in industry as a means of cell disruption and is achieved by passing the cells at high pressures through a small valve or orifice. The Microfluidizer homogenizer (Microfluidics, USA) has been commonly used in the cell disruption optimization work. The effectiveness of the cell disruption step is governed by a few operational parameters (i.e. pressure, number of passages etc..) and will be discussed in the following sub-sections.

The cell breakage mechanism follows first-order kinetics with respect to the number of passes as shown in the equation below:

$\operatorname{Ln}\{\mathrm{Rm}\} /\left\{\mathrm{R}_{\mathrm{m}}-\mathrm{R}\right\}=\mathrm{kN} \mathrm{P}^{\mathrm{a}}$

$\mathrm{R}_{\mathrm{m}}=$ maximum releasable soluble protein

$\mathrm{R}=$ amount of soluble protein released at a given pass

$\mathrm{K}=$ rate dependent on process temperature

$\mathrm{N}=$ number of passes through the homogenizer

$\mathrm{a}=$ exponent indicates the degree of dependency on pressure

\section{$\mathrm{P}=$ pressure}

The breakage as shown in equation [5] is gradual and is dependent on the number of passages through the equipment until all the cells are broken. As the pressure increases, the amount of cell breakage increases accordingly.

\section{Micro-filtration/Ultra-filtration as a method of separation}

As an example of microfiltration optimization, we will be discussing the clarification of an intracellular protein from a bacterial organism. Material from an E.coli bacterial fermentation was used in this discussion. In a typical microfiltration approach, cell concentration and conditioning are usually performed as a start. Diafiltration is a method where equal volumes of buffer are added to the concentrate homogenate (retentate stream) to recover remaining protein in the permeate stream, trapped within the secondary gel layer of the membrane. It is at this stage that the cell concentration is important to minimize the volume and cost of buffer used within the process. If the product is expressed extracellularly, optimization is also performed in a similar fashion where cell concentration and conditioning are performed to recovery the product with the removal of the bioburden load.

Cell concentration is also performed to minimize the lead time of homogenization. It is possible to feed the fermented product directly into the homogenizer in a continuous mode of operation and perform a final concentration and conditioning step of the clarified product at the end. However, in most operations, the homogenization step usually follows the initial removal of cell broth extract. During cell concentration, the increase in cell biomass and media viscosity will reduce the processing flux and recovery. Diafiltration with buffer after concentration is effective in minimizing the viscosity of the cells and thereby increasing the filtration flux of the operation. Usually after homogenization, dilution of the homogenate is performed to adjust the cellular biomass and viscosity to a volume where operations can be performed efficiently in terms of high filtration time and high throughput with minimal buffer consumption cost.

\section{Material and methods}

Cells from an optical density of 40 fermentation are concentrated approximately 5 -fold using a cross-flow filtration unit containing a 0.2 $\mu \mathrm{m}$ pore size cassette and $1.2 \mathrm{~m} 2$ of surface area. The concentrated cells are conditioned in $20 \mathrm{mM}$ Tris, $\mathrm{pH} 8$ buffer and homogenized using a mechanical disruptor at high pressures $(13,000$ to $17,000 \mathrm{psi})$ with several passes. The homogenate is diluted to the original volume and clarified using the cross-flow filtration unit. The clarified material is concentrated approximately 7-8 fold by ultra-filtration using a pore size of $10 \mathrm{kDa}$ and buffer-exchanged several times with equal volumes of buffer before delivering the material to down-stream for further purification. The micro-filtration process for the antigen is shown in Figure 1.

\section{Results}

For a microfiltration operation, a transmembrane pressure of 5-10 psi is generally used (Rusotti, 1995). This pressure is to prevent immediate fouling of the membrane by allowing the polarization cake layer on the membrane to gradually build up. As shown in Figure 2, the flux rate $(\mathrm{LMH})$ was plotted against the concentration at different points during filtration. The flux rate was maintained at a steady state of $27 \mathrm{LMH}$ up to 5 -fold concentration of fermentation cells. The fermentation volume used during processing was $12 \mathrm{~L}$. After a 5 -fold concentration, the flux decreased quickly indicating that there is fouling of the membrane due to the build-up of the gel layer/concentration polarization layer on the 
surface of the membrane. The fouling could also be due to the presence of viscous fermentation broth material that contributed to the decrease of flux as mentioned previously in Equation 2.

The cells were then conditioned with $\mathrm{pH} 8$ buffer through a diafiltration step. As shown in Figure 2, the conditioning effect removed the viscous fermentation broth and, therefore, restored the flux rate to its original value of $27 \mathrm{LMH}(\mathbf{-})$. The fouling as seen in this figure is reversible and the cells could be further concentrated to 10 -fold of its original fermentation volume. The diafiltration step not only aided in improving the flow rate but also conditioned the cells in a suitable buffer for further down-stream processing.

After concentration and homogenization of the cells, clarification of the homogenate was performed to remove the cellular debris from the protein product. The majority of antigen was released at higher pressures at several passes through the homogenizer. The homogenate

\section{Concentration of cells}<smiles>[AlH2]</smiles>

Buffer-exchange cells using $\mathrm{pH} 8$ buffer

Cell lysis by Homogenization

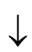

Clarification of homogenate

(Concentration and diafiltration)<smiles>[AlH2]</smiles>

Sterile filter the clarified material

To down-stream for purification

Figure 1: A schematic diagram of the approach taken for the concentration and clarification of protein antigen using micro-filtration.

Flux vs. Concentratration

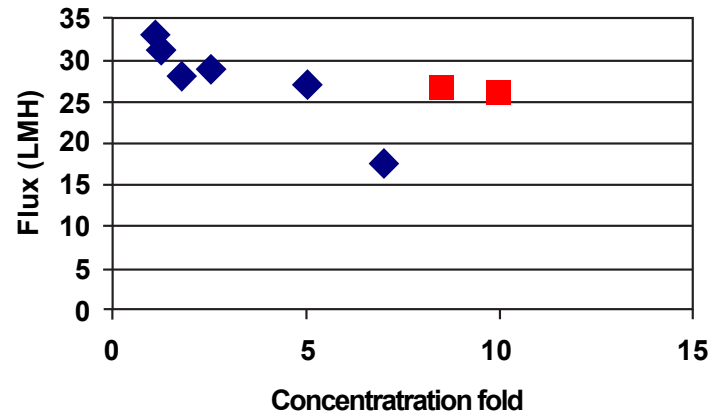

Figure 2: A plot of flux ( $\mathrm{LMH})$ versus concentration fold for the E.coli antigen $1(\downarrow)$. After conditioning of cells, the flux rate could be restored (घ) and cells could be further concentrated to 10 -fold its original fermentation volume. was re-diluted back to the original fermentation volume to decrease the viscosity and concentration of the feed to facilitate the filtration process. Similar to the above optimization, the homogenate was clarified by cross-flow filtration by concentrating the homogenate 5 -fold to recover the release product in the filtrate stream. The clarified protein, during the 5-fold concentration step, was analyzed by HPLC analysis and compared to the protein released after homogenization. About $75 \%$ of the antigen was recovered in the permeate fraction, during this clarification step. After a 5-fold concentration of the homogenate, the homogenate was diafiltered 4 times with equal volumes of buffer and the clarified protein was collected in a separate container. The amount of protein required after diafiltration was quantified by HPLC and compared to the amount of protein released after homogenization. About $22 \%$ of the antigen was recovered during the diafiltration step. As shown in Table 2, the recovery of the clarified material was about $95 \%$ of the initial homogenate yield, according to HPLC quantification. As shown in Table 2, the amount of antigen 1 that could not be recovered was very minimal.

During the diafiltration operation, it is important to determine the amount of product recovered during each step of diafiltration. It is customary to generally perform equal volumes of buffer exchange 5 times to recover the product however, as the scale of operation increases by 10 -fold, this generalization can be very expensive to materialize in production. For example, if we are obtaining approximately $6 \mathrm{~L}$ of diafiltrate at the $12 \mathrm{~L}$ scale, we would likely be obtaining $600 \mathrm{~L}$ of diafiltrate at the $1200 \mathrm{~L}$ scale, if we were scaling up linearly. Although this may be an inaccurate amount, the point is that product recovery needs to be quantified to determine how many diafiltrations are necessary to the process. As demonstrated in Table 3, only 1 diafiltration step is necessary in recovering the majority of the product from the cellular slurry and any further processing does not add value to the operation time and cost, as well as the extra amount of doses produced. As a result, in this example, the concentration step during clarification followed by one diafiltration step was sufficient in recovering the protein product. With further processing, there is also the added requirement of potential cooling of the product to ensure product stability if it is heat-sensitive.

As demonstrated in Table 4, the scaling of microfiltration operation is based on constant flux. Based on the optimization experiments, the flux is used to determine the amount of surface area $\left(\mathrm{m}^{2}\right)$ to be

\begin{tabular}{|c|c|}
\hline Sample Description & $\%$ antigen 1 recovered \\
\hline Homogenized supernatant (12 L) & 100 \\
\hline Homogenized pellet (12 L) & 0 \\
\hline $\begin{array}{c}\text { Clarified permeate during 5-fold concentration of homog- } \\
\text { enate (9.5 L) }\end{array}$ & 75 \\
\hline Diafiltered permeate (4x) (6L) & 22 \\
\hline Unclarified Retentate (0.2 L) & 0.5 \\
\hline
\end{tabular}

Table 2: The recovery of antigen after clarification using cross-flow filtration.

\begin{tabular}{|c|c|}
\hline Sample Description & $\%$ antigen 1 recovered \\
\hline Harvest material & $100 \%$ \\
\hline Clarified permeate & $70 \%$ \\
\hline $1^{\text {st }}$ diafiltration & $25 \%$ \\
\hline $2^{\text {nd }}$ diafiltration & $5 \%$ \\
\hline $3^{\text {rd }}$ diafiltration & $1 \%$ \\
\hline $4^{\text {th }}$ diafiltration & $0.5 \%$ \\
\hline
\end{tabular}

Table 3: Quantifying the amount of product recovered at the concentration step and diafiltration steps in comparison to the amount of product available in the harvest materiala. 
used at the larger scale. Dependent on the desired time of operation, the amount of surface area can be increased or decreased accordingly. In this example, if the total time of operation required is 2 hours, by scaling up the process at constant flux, the amount of surface area of filtration is $4.3 \mathrm{~m}^{2}$. Since the membrane cassettes are purchased in units of $0.6 \mathrm{~m}^{2}$, a total surface area of $4.8 \mathrm{~m}^{2}$ was used for this large-scale operation.

\section{Challenges in using cross-flow micro-filtration during clari- fication}

Not all protein products can be efficiently recovery using a microfiltration operation. It is important to ensure the testing of the operation at small-scale before scaling up the operation. As shown in Table 5, a majority of Antigen 2 protein was being retained and only about $50-60 \%$ of the protein was being clarified in the permeate stream in comparison to the homogenized sample. This phenomenon has been seen in the micro-filtration process for clarification, using flat sheet membrane or hollow-fibre membranes.

Optimization work has been performed to recover the Antigen 2 protein by optimizing at different cross-flow velocities and transmembrane pressures, as shown in Table 6. Despite the optimization of filtration parameters, protein Antigen 2 was not successfully recovered. The recovery of the permeate at this stage was estimated using SDS-PAGE gel analysis using purified samples of known concentration, as determined by the Lowry protein assay. It is noteworthy that the flux rates during microfiltration were still maintained at approximately $28 \mathrm{LMH}$ despite the poor product recovery hence fouling of the membrane was not taking place. In addition, the molecular size of Antigen 2 was similar to Antigen 1 which signifies that the molecular size does not play a dominant role in poor product recovery. It is believed that the biochemical property of the product to be recovered does play a role in the recovery operation. One potential explanation could be in the nature of intermolecular interactions which form within the viscous material of the homogenate. As the homogenate is composed of many protein mol-

\begin{tabular}{|c|c|c|}
\hline Batch Operation & 20L scale & $200 \mathrm{~L}$ scale \\
\hline Volume $(\mathrm{L})$ & 12 & 150 \\
\hline Flux $\left(\mathrm{L} / \mathrm{m}^{2} / \mathrm{hr}\right)$ & 28 & 28 \\
\hline Permeate collected & 20 & 240 \\
\hline Time (hours) & 1.1 & 1.7 \\
\hline Surface area $\left(\mathrm{m}^{2}\right)$ & 0.6 & 4.8 \\
\hline
\end{tabular}

Table 4: Comparing the scalability of the microfiltration process.

\begin{tabular}{|c|c|}
\hline \multicolumn{2}{|c|}{ Cross-flow cassette (Plate-frame technology) } \\
\hline Sample Description & \% of Antigen 2 recovered \\
\hline Homogenized supernatant & 100 \\
\hline Homogenized pellet & 0 \\
\hline Clarified concentrate & 20 \\
\hline Permeate collected & 30 \\
\hline Unclarified retentate & 50 \\
\hline \multicolumn{2}{|c|}{ Hollow-fiber technology } \\
\hline Sample Description & $\%$ of Antigen 2 recovered \\
\hline Homogenized supernatant & 100 \\
\hline Homogenized pellet & 0 \\
\hline Clarified concentrate & 24 \\
\hline Permeate collected & 16 \\
\hline Unclarified retentate & 60 \\
\hline
\end{tabular}

Table 5: Recovery of Antigen 2 during micro-filtration clarification using flat membrane (Top data) and hollow fiber (Bottom data). ecules, it is not unusual that the protein could form larger aggregates either through electrostatic interaction or associated intermolecular attractions (dipole-dipole) within the slurry which may not be easily dissociated [3]. The formation of a larger aggregate coupled with the crossflow velocity across the surface of the membrane may likely prevent the transmission of the product through the membrane. As tangential flow filtration was not scalable for the recovery of Antigen2, in this example, static filtration was used as the method of separation. The rationale here was that if the protein of interest was associated with other different component such as proteins or cellular debris, the method of depth filtration could potentially fractionate the contaminating components in a size-exclusion manner. An assumption in performing depth filtration is that the protein of interest is mildly associated with other components and that through a sieving process; the other components may be removed. Depth filtration has been further investigated as a method for clarification of product from biomass.

\section{Depth-filtration as a method of separation}

Since, there is potential interaction between Antigen 2 protein and cellular particulates within the homogenate, depth filtration was used to remove majority of the cellular debris and contaminating proteins. In order to optimize the clarification process using static filters, a screening test involving different combination of filters (i.e. different pore size membranes and material) was performed for the recovery of Antigen 2 protein. The screening test involved using a manifold dead-end filtration unit with the capability of inserting different types of filter disks with surface area of $12 \mathrm{~cm}^{2}$. The filter disks required only $100 \mathrm{~mL}$ of homogenate. The material used for the screening process was the cells after homogenization. As shown in Table 7, the best combination for the clarification process using static filtration using 2 depth filters $(0.65$ $\mu \mathrm{m}$ and $0.45 \mu \mathrm{m}$ ) followed by a final absolute $0.2 \mu \mathrm{m}$ filter.

The $0.65 \mu \mathrm{m}$ membrane removed about $70 \%$ of the debris from the homogenate. Samples of the filtrate, at each stage of the filtration process, were taken and the amount of debris remaining in the filtrate, after each filtration step was measure to determine how much cellular debris was removed. The majority of the debris was removed during the first 2 filtration steps, using the $0.65 \mu \mathrm{m}$ and $0.45 \mu \mathrm{m}$ filters. The advantage of using depth filters in comparison to absolute filters for debris removal is the reduction in the cost of the operation. Hence, the $0.2 \mu \mathrm{m}$ membrane can be easily downsized with the aid of the 2 initial depth filters.

\begin{tabular}{|c|c|c|}
\hline Cross-flow velocity & $\begin{array}{c}\text { Transmembrane pressure } \\
\text { tested at constant cross- } \\
\text { flow velocity }\end{array}$ & Result \\
\hline 1.1 L.min & \\
\hline 2.2 L.min & $4,8,12,16 \mathrm{psi}^{-1}$ & $\begin{array}{c}50 \% \text { of protein recovered } \\
\text { in the permeate }\end{array}$ \\
\hline 2.2 L.min & $10,15,22 \mathrm{psi}$ & $\begin{array}{c}50 \% \text { of protein recovered } \\
\text { in the permeate }\end{array}$ \\
\hline & $4 \mathrm{psi}$ & $\begin{array}{c}\text { No recovery in permeate, } \\
\text { protein in retentate }\end{array}$ \\
\hline
\end{tabular}

Table 6: A summary of the clarification experiments performed using different pore size membranes during cross-flow micro-filtration.

\begin{tabular}{|c|c|c|c|}
\hline Filter module 1 & Filter module 2 & Filter module 3 & Result of filtration \\
\hline 1) $0.65 \mathrm{um}$ & $0.45 \mathrm{um}$ & $0.2 \mathrm{um}$ & Good flow through \\
\hline 2) $0.8 \mathrm{um}$ & $0.45 \mathrm{um}$ & $0.2 \mathrm{um}$ & Fouling occurred \\
\hline 3) $1.2 \mathrm{um}$ & $0.45 \mathrm{um}$ & $0.2 \mathrm{um}$ & $0.45 \mathrm{um}$ fouled \\
\hline 4) $0.65 \mathrm{um}$ & $0.8 \mathrm{um}$ & $0.2 \mathrm{um}$ & Good flow, low recovery \\
\hline 5) $0.65 \mathrm{um}$ & $0.65 \mathrm{um}$ & $0.2 \mathrm{um}$ & Fouling \\
\hline
\end{tabular}

Table 7: Summary of the filtration screening experiments with different filters for the recovery of Antigen 2. 
The clarification of Antigen 2 using static filtration was performed successfully at the $100 \mathrm{~L}$ scale. As shown in Table 8, Antigen 2 was scaled to the $100 \mathrm{~L}$ size and the clarification recoveries obtained for both antigens were around $80-90 \%$ in comparison to their initial homogenization yield. The process required a final concentration step using an ultra-filtration membrane of molecular weight cut-off of 10 $000 \mathrm{kDa}$ to reduce the volume 7 -fold prior to delivering the material to down-stream for further purification. This reduces the volume and increases ease of handling during processing. Although the recoveries were high for this process, the length of the primary recovery process took 3 working days after fermentation was completed.

\section{Challenges in using depth filtration as a clarification method}

Although the clarification recoveries of Antigen 2 are high using the static filtration method, there are few drawbacks in the scaling up of the process. As mentioned previously, the processing of the clarified material can be long due to the processing time as well as the handling of the equipment (i.e. inserting filter elements, operating the filter housing, cleaning of filter housing), as the equipment sizes (i.e. pumps, filter housing) increase as the scale increases. Another challenge facing the static filtration approach is the cost of filters required for a run at the $100 \mathrm{~L}$ scale. Although the cost is not significant at the $10 \mathrm{~L}$ scale, the disposable cost will significantly increase as the scale increases to 10 or 100 fold. The filter capacity and housing requirements would increase dramatically and waste disposable issues would come into play.

However, the major challenge in the static filtration approach is the robustness of the process. The clarification process is affected by the upstream conditions such as the fermentation growth conditions, as well as the homogenization conditions, which affects the throughput of the clarified material. In one example, E.coli cells were homogenized at a higher pressure of greater than 15,000 psi for several passes through the homogenizer. The homogenization pressure increased the breakage of the cells and formed micro-debris, which fouled the 0.45 um depth filter much quicker than cells homogenized at lower pressures. This is a very important consideration of the application of the static filtration process as the robustness of the process is tightly dependent on its upstream variables such as cell density and homogenization pressure. The static filtration approach however offers the advantage that the clarification process, at the lab scale, is rather simple to operate with limited cleaning of the equipment.

\section{Industrial options of separation using charged membranes and resins}

The area of adsorption chromatography embracing aspects of fixedbed, batch suspension and fluidized-bed contacting complex feedstocks has been well reviewed and utilized in the biotechnology industry [4]. The advances in the design of adsorbents, chemically derivatised ligands with different binding specificities for target bioproducts, have aided in the integration of processing of unclarified feed-stocks in the upstream process and the delivery of purified and high-yielding products for downstream purification. It offers selective advantages

\begin{tabular}{|c|c|}
\hline Sample Description & Amount of Antigen 2 (\%) \\
\hline Homogenized supernatant (100L) & 97 \\
\hline Homogenized pellet & 3 \\
\hline 0.65 um, 0.4 um, 0.2 um filtration (140L) & 90 \\
\hline 10K concentrate (20 L) & 90 \\
\hline
\end{tabular}

Table 8: The clarification recoveries using static filtration of Antigen 2 at $100 \mathrm{~L}$ scale. over the simpler, yet productive, technologies of protein fractionation (i.e. precipitation by solvents, salts, crystallization and aqueous solvent extraction) [5]. In this section, the clarification of the protein of interest from homogenate feed-stock using disposable charge membranes and charge resins in a batch process will be discussed.

\section{Materials and Methods}

\section{Batch Adsorption using charged membrane}

Homogenate was used to pass through 2 types of charged membranes ( $\mathrm{Q}$ and Phenyl Sepharose) at constant cross-flow rate to determine if product could bind to the membranes followed by washing and elution.

\section{Batch Adsorption using charge resins in a tank}

In the area of adsorption chromatography for clarifying feedstocks, the batch adsorption process of mixing adsorbent media with feed-stocks within a tank containing a base with a mesh filter can be an effective and simple way to adsorb target products. Q-Sepharose big beads were used to capture the product, conditioned in a buffer, having a positive charge. The charged adsorbent is subsequently washed with a suitable buffer to remove excess protein or cellular contaminants. A mesh filtration membrane that is smaller than the bead size is employed to allow the washing of excess protein and contaminants while retaining the protein of interest. This batch clarification method can allow desorption of product from the beads using a higher salt buffer and the beads can be regenerated for re-use in similar batch suspension procedures (Bierau et al., 2001). The clarified material is further concentrated, using size exclusion ultra filtration membrane, and buffer-exchanged prior to further purification using higher resolution techniques. Batch adsorption at the process scale offers an opportunity to exploit cheaper adsorbents which may serve as an effective alternative to process scale fixed and fluidized-bed applications.

\section{Results}

\section{Recovery of Antigen 2 using charged membranes}

Charged membranes did not demonstrate efficient binding and elution of antigen. Overall, the capacity of antigen was $0.5 \mathrm{mg}$ per $\mathrm{cm} 2$ of membrane. Even though optimization of $\mathrm{pH}$, buffer ionic strength, cross-flow velocity and binding time duration, this application of using charged membranes to clarify the antigen was not suitable option for the production scale.

\section{Recovery of Antigen 2 using resins within batch adsorption tank}

As shown in Table 9, the overall \% recovery demonstrated that the antigen recovery was higher using batch clarification than using the microfiltration process. It is noteworthy that batch clarification needs to be optimized at the small-scale to determine if the process is suitable in terms of purity, recovery and cost before scaling up the process to the production scale.

After the fermentation has been completed, the harvest culture was concentrated and conditioned in buffer followed by high pressure homogenization. The clarification of the homogenate was compared using 2 different methods, batch adsorption and microfiltration at the production scale, as shown in Table 10. The capital cost between the 2 methods (i.e. batch adsorption and microfiltration) is not significantly different. The buffer consumption for the batch adsorption step is more than the microfiltration step due to the additional buffers used for con- 
Citation: Lee T, Amore TD (2011) Membrane Separation Theoretical and Applicable Considerations for Optimum Industrial Bioprocessing. J Bioprocess Biotechniq 1:101e doi: 10.4172/2155-9821.1000101e

Page 8 of 8

ditioning, washing and elution. However, the total buffer volume used for both recovery and purification step is not significantly different. The $\%$ recovery for both methods was similar with an average of approximately $75 \%$ product recovery in comparison to the initial fermentation yield. The big difference between the 2 methods was the operation performance. The batch adsorption method was more laborious than microfiltration, as there was much effort in assembling the tank, pumping the beads into the tank, conditioning and washing of the beads as well as collecting the product and beads at the production scale. The microfiltration process was more automated so there was less handling of the product during the operation.

The overall purification capital, filter and resin costs were significantly reduced due to a higher purity achieved after batch adsorption, as shown in Table 10. The significant benefit is also that the overall recovery using the batch adsorption method is significantly higher than microfiltration while the overall purity is similarly high at $98 \%$. From the analysis, the batch adsorption method can reduce capital and resin costs during purification and can deliver a higher final product recovery while maintaining high product purity.

\section{Conclusion/Recommendations}

A summary table, as shown in Table 11, outlines the advantages and challenges that can be associated with the different technologies. Although each technology has its advantages and challenges, it is important to evaluate these technologies at a small-scale to determine their feasibility. Large-scale demonstration runs will be helpful to evaluate

\begin{tabular}{|c|c|}
\hline Antigen 2 & $\%$ recovery HPLC \\
\hline Homogenate & 100 \\
\hline $1^{\text {st }}$ wash: Amount in supernatant & 10 (product loss) \\
\hline low-salt wash & 12 ( product loss) \\
\hline Elution & 80 \\
\hline 0.2 um filtered & 72 \\
\hline
\end{tabular}

Table 9: Clarification recovery of Antigen 2 using batch adsorption tank.

\begin{tabular}{|c|c|c|}
\hline & Batch Adsorption & Microfiltration \\
\hline \multicolumn{3}{|c|}{ Primary recovery step (per antigen) } \\
\hline $\begin{array}{c}\text { Number of production runs to } \\
\text { generate data }\end{array}$ & 4 & 4 \\
\hline Capital cost & $\begin{array}{l}\$ 220,000 \text { (TFF unit + batch } \\
\text { adsorption tank) }\end{array}$ & $\$ 200,000$ (only TFF unit) \\
\hline Resin cost & $\begin{array}{c}\$ 2,100 \text { (per run) } \\
\text { Resin is suitable for } 10 \text { runs }\end{array}$ & None \\
\hline $\begin{array}{c}\text { Cost of } 0.2 \text { um filters }(2.4 \mathrm{~m} 2 \\
\text { surface area used })\end{array}$ & $\begin{array}{l}\quad \$ 800 \text { (per run) } \\
\text { Filters suitable for } 10 \text { runs }\end{array}$ & $\begin{array}{l}\$ 800 \text { (per run) } \\
\text { Filters suitable for } 10 \text { runs }\end{array}$ \\
\hline $\begin{array}{c}\text { Total buffer volume used } \\
\text { for recovery for condition- } \\
\text { ing, cleaning, washing \& } \\
\text { elution (L) }\end{array}$ & $1685 \pm 96 \mathrm{~L}$ & $1270+50 \mathrm{~L}$ \\
\hline $\begin{array}{l}\% \text { recovery (in comparison to } \\
\text { fermentation yield) }\end{array}$ & $79 \pm 18 \%$ & $71 \pm 19 \%$ \\
\hline \multicolumn{3}{|c|}{ Purification step (per antigen) } \\
\hline $\begin{array}{c}\text { Capital cost (Skid, column, } \\
\text { TFF unit) }\end{array}$ & $\$ 350,000$ & $\$ 437,500 \pm 15,000$ \\
\hline Resin cost & $\$ 3,475 \pm 881$ (per run) & $\$ 11,125 \pm 581$ (per run) \\
\hline $\begin{array}{l}\text { Cost of } 10 \mathrm{~K} \text { filters ( } 2.4 \mathrm{~m} 2 \\
\text { surface area used })\end{array}$ & $\$ 800$ (per run) & $\$ 800$ (per run) \\
\hline Final purity $\%$ & $98 \pm 2$ & $99 \pm 1$ \\
\hline $\begin{array}{l}\text { Total buffer volume used for } \\
\text { purification for conditioning, } \\
\text { cleaning, washing \& elution } \\
(L)\end{array}$ & $1268 \pm 439 \mathrm{~L}$ & $1860 \pm 256 \mathrm{~L}$ \\
\hline
\end{tabular}

Table 10: Summary of the comparison of process economics between batch adsorption and microfiltration at the production scale.

\begin{tabular}{|c|c|c|}
\hline Technology & Advantage & Challenges \\
\hline $\begin{array}{c}\text { Cross-flow microfiltration (i.e. } \\
\text { plate-frame, hollow-fiber) }\end{array}$ & $\begin{array}{c}\text { Clarification recovery of } 90 \% \\
\text { can be achieved and the } \\
\text { operation is scalable. }\end{array}$ & $\begin{array}{c}\text { Protein recovery is dependent } \\
\text { on the protein biochemical } \\
\text { properties. }\end{array}$ \\
\hline Static dead-end filtration & $\begin{array}{c}\text { Clarification recovery of } \geq \\
90 \% \text { can be achieved by } \\
\text { using a series of depth and } \\
\text { absolute filters. }\end{array}$ & $\begin{array}{c}\text { The operation is difficult at a } \\
\text { larger scale (i.e. } 200 \mathrm{~L} \text { ) and } \\
\text { there will be more expensive } \\
\text { capital (housings, pipings, } \\
\text { filters) and operational costs } \\
\text { to be considered. }\end{array}$ \\
\hline $\begin{array}{c}\text { Batch Clarification using ion- } \\
\text { exchange resins }\end{array}$ & $\begin{array}{c}\text { Clarification recovery of } \geq \\
90 \% \text { can be achieved. The } \\
\text { operation is the cheapest at } \\
\text { the large-scale in comparison } \\
\text { to micro or static filtration }\end{array}$ & $\begin{array}{c}\text { Automation of this method } \\
\text { may aid in reducing the } \\
\text { amount of manual manipula- } \\
\text { tions at the larger scale. }\end{array}$ \\
\hline
\end{tabular}

Table 11: A summary of the different clarification technologies explored and thei advantages and challenges when applied to large-scale manufacturing.

the recovery efficiencies and business benefits before transferring the process to production.

\section{References}

1. Russotti G, Osawa E, Sitrin RD, Buckland BC, Adams WR, et al. (1995) Pilot-scale harvest of recombinant yeast employing microfiltration:a case study. Journal of Biotechnology 42: 235-246.

2. Stephanopoulos G (1997) Scale-up in Biotechnology 3: 500.

3. Yadav S, Shire SJ, Kalonia DS (2010) Factors affecting the viscosity in high con-centration solutions of different monoclonal antibodies. Journal of Pharmaceutical Scicnece 99: 4812-4829.

4. Lyddiatt A (2002) Process chromatography: current constraints and future options for the adsorptive recovery of bioproducts.Current Opinion in Biotechnology 13: 95-103.

5. Thommes J, Etzel M (2007) Alternatives to chromatographic separation.Biotech-nology Progress 23:42-45

6. Atkinson B, Mavituna F (1991) Gas-Liquid Mass Transfer and Mixing in Biochemi-cal Engineering and Biotechnology Handbook Edition 2 (Stockton Press eds), Chapters 12 and 20

7. Chen X, Cen $P$ and Chen $J$ (2005) Enhanced production of huan epidermal growth factor by a recombinant Escherichia coli integrated with In Situ exchange of acetic acid by macroporous ion-exhcnage resin. Journal of Bioscience and Bio-engineering 100: 579-581.

8. Datar R (1985) The separation of intracellular soluble enzymes from bacteria cell debris by tangential flow membrane filtration. Biotechnology Letters 7 : 471-476.

9. Doran P (1995) Mass transfer, p. 190-217. In Bioprocess Engineering Principles, Academic Press Limited, USA.

10. Hughes DJ, Cui Z,Zhanfeng Cui Field RW,Tirlapur UK (2007) Membrane fouling by cell-protein mixtures: In Situ characterisation using multi-photon microscopy. Biotechnology and Bioengineering 96: 1083-1091.

11. Sethi S and Graham J (2002) Microfiltration of primary effluent for clarification and microbial removal. Environmental Engineering Science 19: 467-475. 